\title{
Thermal Stability Investigation of PEDOT Films from Chemical Oxidation and Prepolymerized Dispersion
}

\section{Yang JIN, ${ }^{a}, *$ Qingping CHEN, ${ }^{a}$ and Philip LESSNER}

\author{
a KEMET Electronics (Suzhou) Co., Ltd., No. 99 Yangpu Road, SIP, Suzhou, Jiangsu 215024, PRC \\ b KEMET Electronics Corporation, 2835 Kemet Way, Simpsonville, South Carolina 29681, USA \\ * Corresponding author: yangjin@kemet.com
}

\begin{abstract}
Poly(3,4-ethylenedioxythiophene) (PEDOT) films were produced by chemical oxidative polymerization (in-situ PEDOT) and coating aqueous dispersion (slurry PEDOT). Sheet resistance measured before and after heat treatment showed that slurry PEDOT film remained stable in air while in-situ film degraded resulting in a significant increase in resistance. Excellent stability of slurry film was credited to its PEDOT-rich core, Poly(styrenesulfonic acid) (PSS)-rich shell structure, and high molecular weight $\left(\mathrm{M}_{\mathrm{w}}\right)$ PSS dopant while the degradation of in-situ PEDOT was attributed to oxidation by oxygen in air. Thermal analysis data supported this hypothesis. Fourier Transform Infrared (FT-IR) spectrometry and X-ray photoelectron spectroscopy (XPS) results indicated that $\mathrm{C}=\mathrm{C}$ bond breaking and decreased doping level were responsible for poor stability of in-situ film in air.
\end{abstract}

(C) The Electrochemical Society of Japan, All rights reserved.

Keywords : PEDOT, Sheet Resistance, Thermal Stability

\section{Introduction}

PEDOT has been attracting much attention as conducting polymer during the last decades because of its wide applications. ${ }^{1}$ Due to its high conductivity, self-healing property and benign failure mode, it has been used as cathode material in capacitors replacing manganese dioxide or liquid electrolytes. In the 1990s, first solid electrolytic capacitor based on PEDOT was commercialized. ${ }^{2}$ PEDOT is now the first choice of conducting polymer materials used in capacitor field due to its simplicity of processing and good thermal stability. Generally, PEDOT film can be obtained by chemical oxidative polymerization of 3,4-ethylene-dioxythiophene (EDOT) or coating easily processible dispersion formed by PEDOT mixed mainly with PSS. Despite the common understanding of insitu and slurry PEDOT, material differences especially for thermal stability are not fully investigated. In this study, we demonstrate their stability difference during thermal treatment in air and $\mathrm{N}_{2}$ atmospheres. Stabilization and degradation mechanism will be presented.

\section{Experimental}

\subsection{Materials}

EDOT monomer, Clevios ${ }^{\mathrm{TM}} \mathrm{M}$ V2, oxidizer solution of ferric toluene sulfonate in ethanol, Clevios ${ }^{\mathrm{TM}} \mathrm{C}-\mathrm{E}$, and an aqueous dispersion of PEDOT/PSS, Clevios ${ }^{\mathrm{TM}} \mathrm{K}$ V2 HV, all from Heraeus, were used as received. Substrate material was PET film. A fast drying silver based conductive paint, Leitsilber 200, was purchased from Ted Pella, Inc.

\subsection{In-situ and Slurry Film Preparation}

Procedure of in-situ PEDOT film preparation: substrate was immersed in oxidizer solution for 5 seconds, then taken out and dried for 30 minutes in ambient condition (about $25^{\circ} \mathrm{C}, 50 \%$ relative humidity). This was followed by dipping in monomer. Reactant system was dried for one hour and washed sequentially with ethanol, deionized water and ethanol. Obtained film is in doped state with tosylate ion as counter-ion.
Procedure of slurry PEDOT film preparation: approximately $0.2 \mathrm{~g}$ of PEDOT/PSS dispersion was casted on PET by a spiral wound bar coater to produce $61 \mu \mathrm{m}$ wet film. Coated film was dried at $130^{\circ} \mathrm{C}$ for 20 minutes.

\subsection{Measurement}

Two narrow parallel conductive coating strips $20 \mathrm{~mm}$ long and $20 \mathrm{~mm}$ apart were coated on the dried films with Leitsilber 200 paint. Samples were dried at ambient condition for one hour. Sheet resistance was measured by a multimeter and reported result is the average of four samples.

Differential scanning calorimetry (DSC), thermogravimetric analysis (TGA) measurements were carried out with Perkin-Elmer Pyris- 1 and TGA-7 under air and nitrogen gas flow with $10^{\circ} \mathrm{C} \mathrm{min}{ }^{-1}$ heating rate. IR spectra were recorded on a BURKER VERTEX-70 FT-IR spectrophotometer using $\mathrm{KBr}$-disk method. XPS was performed using a SHIMADZU: AXIS-ULTRA DLD spectrometer.

\section{Results and Discussion}

Sheet resistance of fresh and thermally treated in-situ and slurry PEDOT films is listed in Table 1. In air, slurry PEDOT film showed stable reading even after $16 \mathrm{~h}$ at $175^{\circ} \mathrm{C}$. This is consistent with the report by L. Groenendaal et al. ${ }^{3}$ which indicated stable conductivity of slurry type PEDOT film after $1000 \mathrm{~h}$ at $100^{\circ} \mathrm{C}$. As for the in-situ

Table 1. Sheet resistance of in-situ and slurry PEDOT films pre and post thermal treatment.

\begin{tabular}{cccc}
\hline \multirow{2}{*}{$\begin{array}{c}\text { PEDOT } \\
\text { material }\end{array}$} & Atmosphere & \multicolumn{2}{c}{ Sheet resistance $(\Omega / \square)$} \\
\cline { 3 - 4 } & & $\begin{array}{c}\text { Before } \\
\text { treatment }\end{array}$ & $\begin{array}{c}\text { Heated at } \\
175^{\circ} \mathrm{C} \text { for } 16 \mathrm{~h}\end{array}$ \\
\hline \multirow{2}{*}{ In-situ film } & Air & 63.9 & $1.40 \times 10^{6}$ \\
& $\mathrm{~N}_{2}$ & 43.7 & 100 \\
\multirow{2}{*}{ Slurry film } & Air & 65.4 & 94.2 \\
& $\mathrm{~N}_{2}$ & 68.6 & 86.5 \\
\hline
\end{tabular}



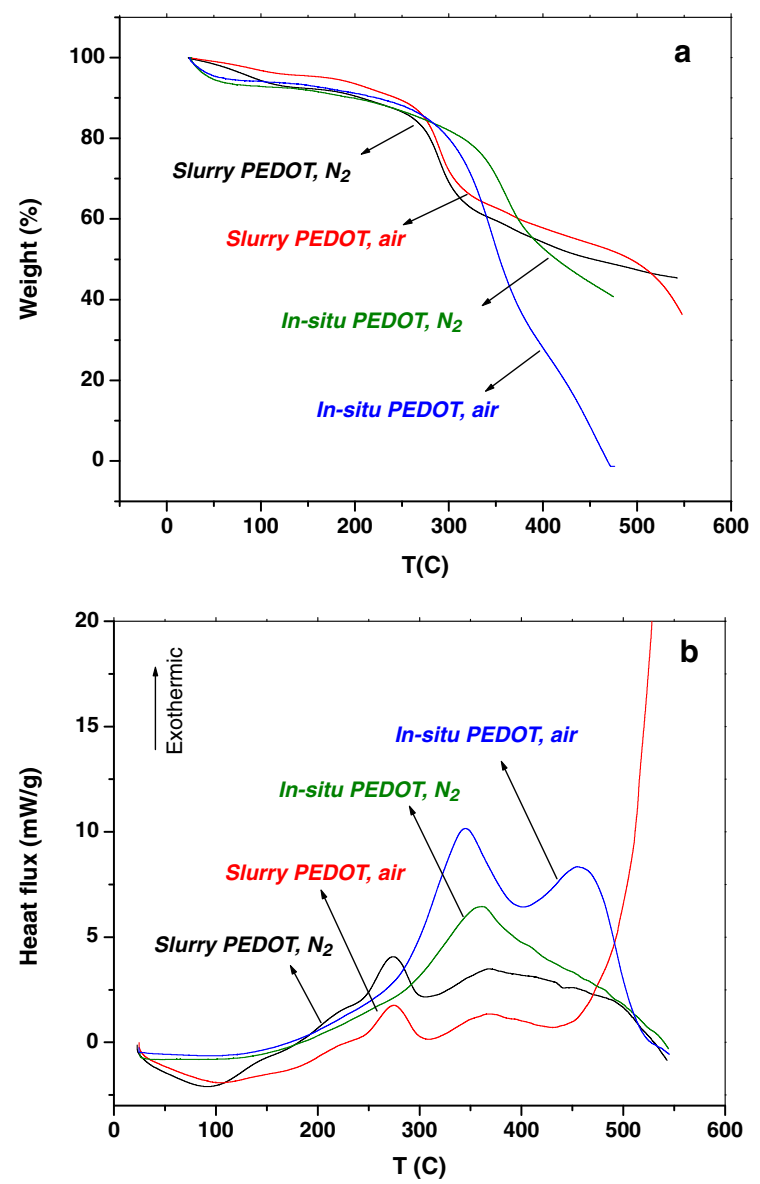

Figure 1. (Color online) TGA (a) and DSC (b) curves of in-situ and slurry PEDOT under air and nitrogen gas flow.

film undergo same thermal treatment in air, sheet resistance changed from less than $70 \Omega$ to $1 \mathrm{M} \Omega$ level. Change of film appearance from dark blue to brown was also observed. In contrast, both in-situ and slurry PEDOT films showed relatively stable resistance in nitrogen. It can be concluded that poor thermal stability of in-situ film is related to oxygen. E. Reed et al. ${ }^{4}$ reported that equivalent series resistance (ESR) of tantalum solid electrolytic capacitors with in-situ PEDOT as cathode layer increased significantly when PEDOT layer is exposed to oxygen under elevated temperature. Superior thermal stability of slurry PEDOT makes it a great candidate for applications in electronic devices targeted for high temperature environment.

Excellent thermal stability of slurry PEDOT is first attributed to its molecular structure in solid film. Slurry film made from PEDOT/ PSS dispersion was suggested to grains with a hydrophobic, electrically conductive PEDOT-rich core and a hydrophilic insulating PSS-rich shell. ${ }^{5}$ With this morphology, PEDOT segment surrounded by PSS material will have less opportunity to contact and react with oxygen. Furthermore, PSS ion has a less tendency to de-dope due to its high $\mathrm{M}_{\mathrm{w}}$ compared to tosylate ion dopant in insitu film. Difference observed by others may be due to formulation, film preparation and heat condition. ${ }^{6,7}$

Figure 1 shows the TGA [Fig. 1(a)] and DSC [Fig. 1(b)] results of in-situ and slurry PEDOT under air and nitrogen gas flow. For slurry PEDOT, both TGA and DSC curves show similar behavior in the region lower than $450^{\circ} \mathrm{C}$. The weight loss in TGA and heat flux peak in DSC around $290^{\circ} \mathrm{C}$ is due to decomposition of PSS component as well as other polymeric additives in the formulation. Additional weight loss and heat flux peak at temperature higher than $350^{\circ} \mathrm{C}$ may be due to carbon-carbon bond breakage. ${ }^{8}$ Under air flow condition, further significant weight decrease and exothermal peak
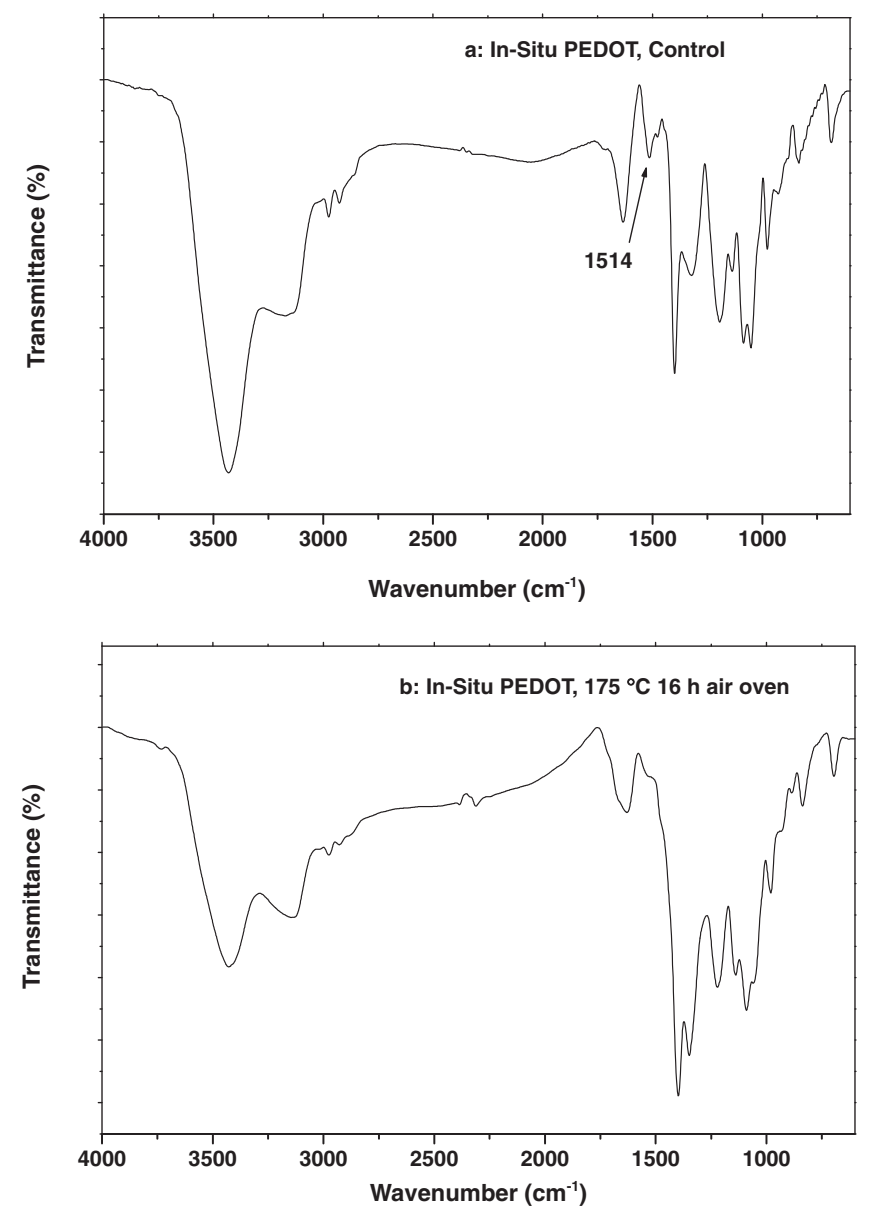

Figure 2. FT-IR spectra of in-situ PEDOT film: (a) fresh material (b) post $175^{\circ} \mathrm{C} 16 \mathrm{~h}$ treatment in air oven.

in DSC can be observed above $450^{\circ} \mathrm{C}$, which may imply the oxidation reaction of exposed PEDOT molecule once the PSS layer disappeared.

TGA result in Fig. 1(a) shows that doped in-situ PEDOT material in both air and $\mathrm{N}_{2}$ atmosphere remained stable up to around $250^{\circ} \mathrm{C}$. Major weight loss occurred in the region between 280 and $400^{\circ} \mathrm{C}$. Similar TGA data were previously reported. ${ }^{9}$ In-situ PEDOT remained more stable in $\mathrm{N}_{2}$ as indicated by a higher decomposition temperature and no further serious exothermal peak at higher temperature $\left(>400^{\circ} \mathrm{C}\right)$.

FT-IR and XPS were used to investigate the change of molecular structure and doping level of in-situ PEDOT film. FT-IR spectra before and after heating in air are shown in Fig. 2. In $\mathrm{N}_{2}$ environment, the spectrum is similar to the fresh sample. Vibrational band at $1323 \mathrm{~cm}^{-1}$ is due to $\mathrm{C}-\mathrm{C}$ stretching of thiophene ring and $1186,1139,1080$, and $1053 \mathrm{~cm}^{-1}$ are assigned to C-O-C stretching in ethylene dioxy group. Vibration modes of the C-S bond can be seen at 977,834 , and $686 \mathrm{~cm}^{-1} \cdot \cdot^{10,11}$ The absorption band at $1514 \mathrm{~cm}^{-1}$ is due to stretching mode of $\mathrm{C}=\mathrm{C}$ in thiophene ring, which is not observed post air oven treatment. The oxidation of $\mathrm{C}=\mathrm{C}$ bonds is believed to be the reason for significant resistance increase of in-situ PEDOT heated in air, which is consistent with previous hypothesis. ${ }^{8}$

Figure 3 shows S(2p) XPS spectra of in-situ PEDOT material with and without heating in air. Binding energy peaks at 163.8 and $164.9 \mathrm{eV}$ correspond to spin-split doublets of sulfur atom from PEDOT. Higher binding energy at $169.0 \mathrm{eV}$ includes two kinds of sulfur peaks: ionic $(168.8 \mathrm{eV})$ and neutral $(167.5 \mathrm{eV})$ tosylate. The ratio between $\mathrm{PEDOT}^{+} \mathrm{OTs}^{-}$and PEDOT signals gives a direct estimation of doping level. ${ }^{12}$ The concentration of dopants in fresh 

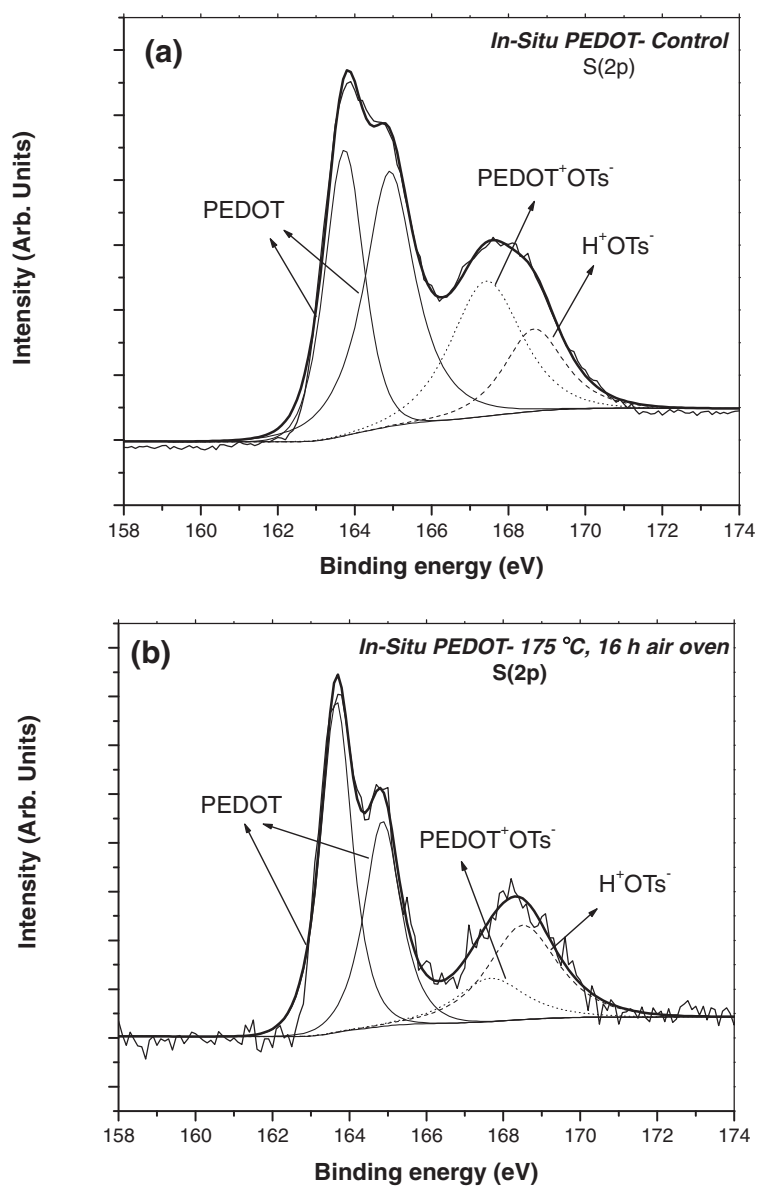

Figure 3. XPS S(2p) spectra of in-situ PEDOT films in fresh (a) and after heat treatment at $175^{\circ} \mathrm{C}$ air oven for $16 \mathrm{~h}(\mathrm{~b})$. in-situ PEDOT is estimated to be $27 \%$, and it changed to $11 \%$ after heating in air. This is another reason for the significant increase in sheet resistance of in-situ PEDOT heated in air.

\section{Conclusion}

Thermal stability of in-situ and slurry PEDOT films was compared by sheet resistance measurement. When heated in air, in-situ PEDOT showed significant deterioration of conductivity while slurry PEDOT remained stable. Overall degradation mechanism is related to oxidation by oxygen. The degradation process was investigated by thermal analysis. Excellent stability of slurry PEDOT is attributed to its PEDOT-rich core and PSS-rich shell structure. XPS and FT-IR results revealed that poor stability of insitu PEDOT film in air can be ascribed to the decrease of doping level and molecular chain breaking. Fruit of this investigation is potential utilization of slurry PEDOT material as capacitor cathode to expand the application at high temperature.

\section{References}

1. S. Kirchmeyer and K. Reuter, J. Mater. Chem., 15, 2077 (2005).

2. Y. Kudoh, K. Akami, and Y. Matsuya, Synth. Met., 102, 973 (1999).

3. L. Groenendaal, F. Jonas, D. Freitag, H. Pielartzik, and J. R. Reynolds, $A d v$. Mater, 12, 481 (2000).

4. E. Reed, J. Chen, J. Marshall, J. Paulsen, and R. Weisenborn, Proceedings from 2003 CARTS-Europe Conference, Electronics Components, Assemblies and Materials Association, Arlington, VA, USA (2003).

5. U. Lang, E. Müller, N. Naujoks, and J. Dual, Adv. Funct. Mater, 19, 1215 (2009).

6. J. Huang, P. F. Miller, J. C. de Mello, A. J. de Mello, and D. D. C. Bradley, Synth. Met., 139, 569 (2003).

7. E. Vitoratos, S. Sakkopoulos, E. Dalas, N. Paliatsas, D. Karageorgopoulos, F. Petraki, S. Kennou, and S. A. Choulis, Org. Electron., 10, 61 (2009).

8. A. Elschner, S. Kirchmeyer, W. Lövenich, U. Merker, and K. Reuter, PEDOT: Principles and Applications of an Intrinsically Conductive Polymer, CRC press, Taylor \& Francis Group, Boca Raton, London, New York, p. 124 (2011).

9. L. Z. Zhan, Z. P. Song, J. Y. Zhang, J. Tang, H. Zhan, Y. H. Zhou, and C. M. Zhan, Electrochim. Acta, 53, 8319 (2008).

10. X. M. Yang, S. M. Shang, L. Li, X. M. Tao, and F. Yan, Polym. Adv. Technol., 22, 1049 (2011).

11. S. Vinod Selvaganesh, J. Mathiyarasu, K. L. N. Phani, and V. Yegnaraman, Nanoscale Res. Lett., 2, 546 (2007).

12. T. Y. Kim, C. M. Park, J. E. Kim, and K. S. Suh, Synth. Met., 149, 169 (2005). 